ICOSITER 2018 Proceeding

Journal of Science and Applicative Technology

\title{
Digital Rock Physics Investigation in Outcrop Sandstone Reservoir
}

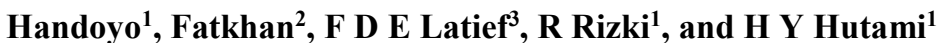 \\ ${ }^{1}$ Geophysical Engineering Institut Teknologi Sumatera, South Lampung, Indonesia \\ ${ }^{2}$ Geophysical Engineering Institut Teknologi Bandung, West Java, Indonesia \\ ${ }^{3}$ Earth Science Institut Teknologi Bandung, Indonesia \\ Email: handoyo.geoph@tg.itera.ac.id
}

\begin{abstract}
Porosity and permeability of the reservoir rocks can be calculated using digital rock physics. This technique is one of the fastest and effective ways to calculate the value of porosity and permeability based on rock sample images. The samples observed in this paper were gathered from the outcrop of oil-filled sandstone formation. The technology of digital rock physics allowed us to predict the physical properties, mainly porosity and permeability, in the outcrop sandstone samples. The digital image model displayed in the $2 \mathrm{D}$ and $3 \mathrm{D}$ images and the complexity of pore geometry as well. From the image, we develop the digital simulation to predict the value of porosity and permeability in the 3D samples. By applying this method, we have confirmed that the target area of this research is potential to be a reservoir, which is porous and clean.
\end{abstract}

Keywords: digital rock physics, simulation, porosity, permeability

\section{Introduction}

Research on reservoir rock characterization is very important to be done to determine the nature of the reservoir rock. Reservoir rock characteristics can be known from the value of physical parameters in reservoir rocks. Research on the effect of sample size dimensions on the variation of porosity and permeability values has been carried out by Dvorkin [4] and Saxena [9]. Paper Dvorkin [4] discusses the effect of sample size on porosity variation, while Saxena's paper [9] discusses the effect of porescale on permeability values. The purpose of writing this paper is to describe the effect of the dimensions of the sample size on the distribution of the value of physical parameters in rocks such as porosity, tortuosity, and permeability.

In this study, the value of variations in physical parameters (porosity and permeability) on sandstone samples will be calculated and analyzed. Calculation of physical rock parameter values is done by approaching digital rock physics in Ngrayong Formation outcrop sandstone.

\section{Basic Theory}

Some physical quantities are then calculated from the digital samples. Two of the many physical parameters that are generally considered important in reservoir rock characterization are porosity and 
permeability. Porosity is the ratio between the $V_{\text {pore }}$ pore volume to the total $V_{\text {total }}$ rock volume, which can be written as:

$$
\phi=\frac{V_{\text {pore }}}{V_{\text {total }}}=1-\frac{V_{\text {matriks }}}{V_{\text {total }}}
$$

Then, the value of the specific internal surface area of the rock can be calculated as the ratio between the square pore area to the total rock volume. Formed as:

$$
S=\frac{S_{\text {pore }}}{V_{\text {total }}}
$$

The tortuosity value $\tau$ can be calculated as a porosity function $\phi$ using the equation given by Berryman[2], namely:

$$
\tau=\frac{1+\phi^{-1}}{2}
$$

The tortuosity value in equation (3) is a function of total porosity without paying attention to the pore type (geometry and structure). After knowing the value of porosity, surface area, and tortuosity, then the value of sandstone permeability is calculated using the Kozeny-Carman equation written as:

$$
k_{a b s}=\frac{1}{2} \frac{\phi^{3}}{S^{2} \tau^{2}}
$$

Equation (4) is the relationship between permeability $k$ as a function of porosity, surface area, and tortuosity of rock.

\section{Data and Method}

\subsection{Data}

The study in Outcrop Ngrayong sandstone samples scaled a range of grain size $(0.05-0.5 \mathrm{~mm})$ and porosity $(30 \%-35 \%)$. The core data under scanned from CT scanner (Figure 1) already calculated the value of porosity and permeability in the laboratory. From the lab test, the porosity value of core data is $33 \%$ and the permeability is $5500 \mathrm{mD}$ approximately. 


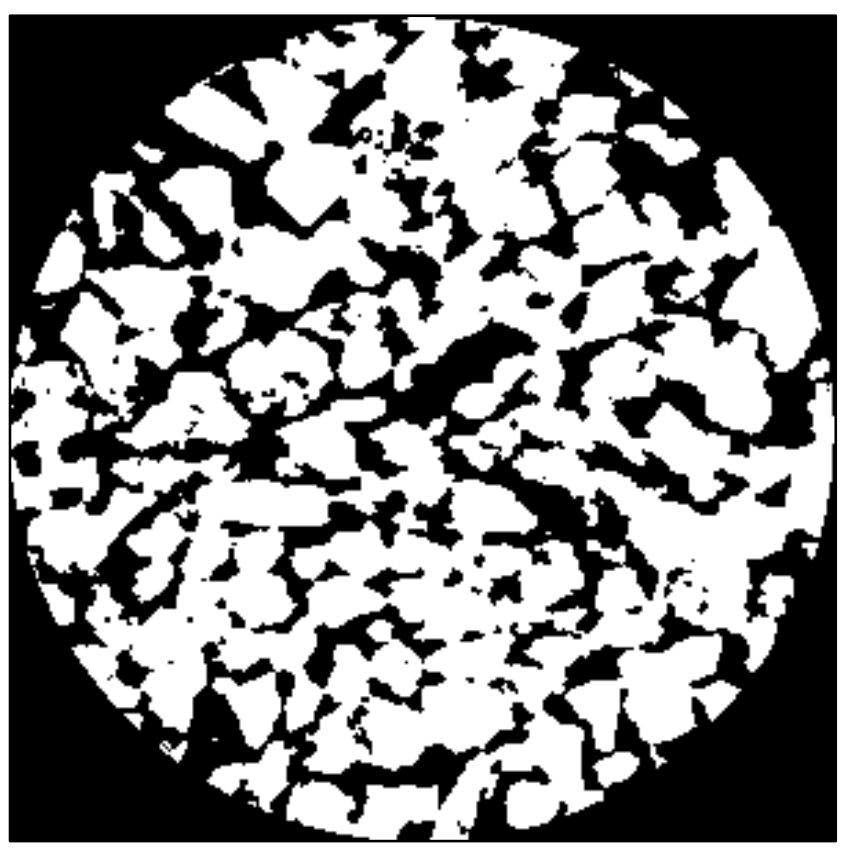

Figure 1. The image of the core data of the outcrop Ngrayong Formation

\subsection{Method}

The standard DRP workflow consists of four major steps: 3-D image acquisition, artifact/ noise removal, segmentation, and the computation of rock properties (Figure 2). A computerized tomography (CT) scan uses tomographic reconstruction to combine a series of X-ray images taken from different angles of the scanned object. Traditional medical CT scanners generate low-resolution images of rock samples. Hence, DRP simulations commonly use micro-CT images. A micro-CT scanner uses a small $\mathrm{X}$-ray spot that allows for resolving details as small as a few micrometers in size.

Several artifacts can appear on CT scans and consequently affect the simulation process. The most frequently encountered artifact is beam hardening, which causes the edges of an object to appear brighter than its center. The lower energy components of the X-ray spectrum are more easily attenuated or even completely absorbed when traveling through a dense part.

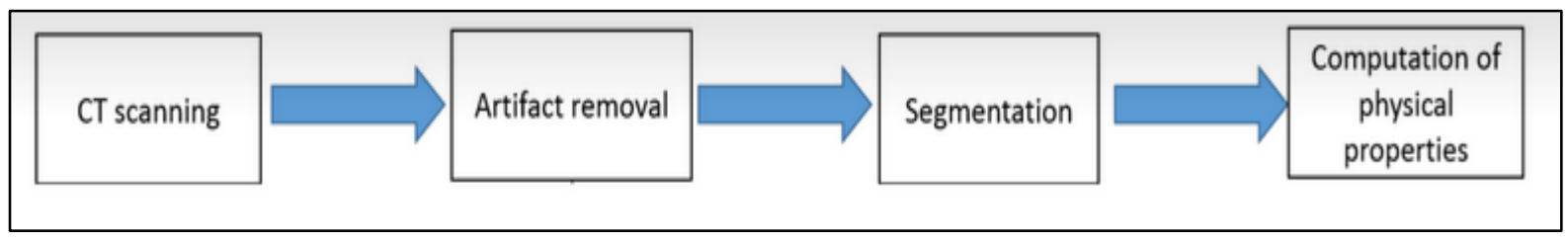

Figure 2. Workflow of Digital Rock Physics technique

Image segmentation is not a trivial problem. In DRP, our goal is to classify CT scan voxels into one of two or more mineral and pore classes. In an ideal situation, histograms of CT rock scan images are multi-modal, with distinct peaks representing each mineral/ void in the scans. In practice, image histograms show more complex behavior, in which the range of gray levels between histogram peaks is continuous.

\section{Results and Discussion}

The result of the sample images shown in Figure 3. The original image divided in area of interest to more detail analysis. The dimension of this area is $300 \times 300$ pixels and again we make the more detail 
image with dimension $150 \times 150$ pixels. Then we select the image and continue the next process: thresholding, noise deleting, and filtering. Next, we obtain the 2D image in many slices and we develop the 3D image as a cube. The small sub-cubes were constructed from the main cube of a detailed images.

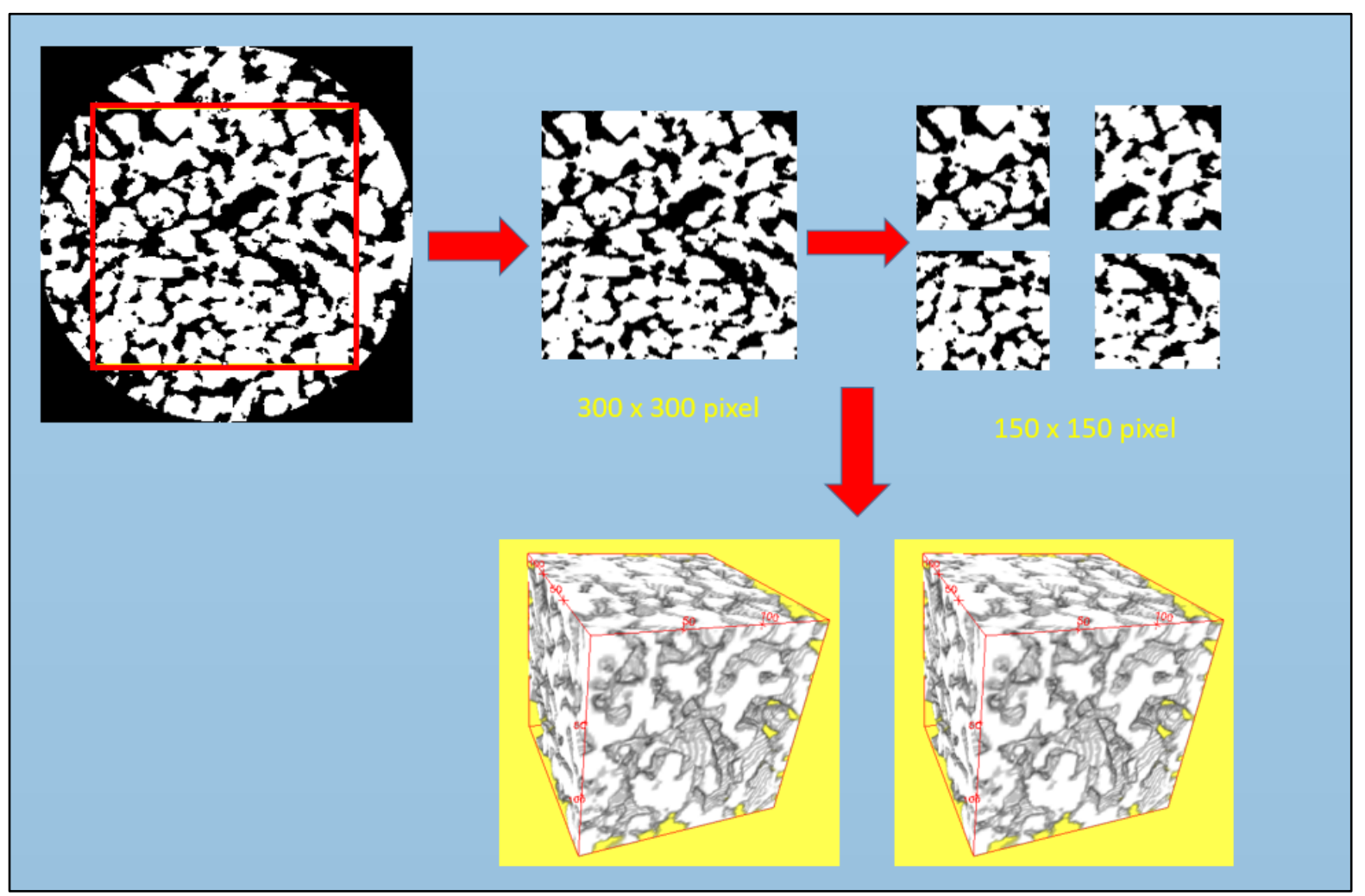

Figure 3. Illustration to develop the interest area in 2D and 3D and also to make the sub-area. After the image processing an segmentation, we continue in image simulation process to calculate the physical properties. A simple way to calculate that value is using MATLAB coding or free software (FiJi). The result of physical properties calculation is shown in Table 1.

Table 1. The result of the physical properties of Ngrayong sample

\begin{tabular}{|c|c|c|c|c|}
\hline No Sample & $\begin{array}{c}\text { Total } \\
\text { porosity }\end{array}$ & $\begin{array}{c}\text { Surface Area } \\
(\mathbf{1} / \mathbf{m m})\end{array}$ & Tortuosity & $\begin{array}{c}\text { Permeability } \\
(\mathbf{m D})\end{array}$ \\
\hline 1 & 34.33 & 1.08 & 1.96 & 4593 \\
\hline 2 & 33.32 & 1.18 & 1.77 & 4064 \\
\hline 3 & 33.12 & 1.05 & 2.01 & 4132 \\
\hline 4 & 34.76 & 1.19 & 1.94 & 4029 \\
\hline 5 & 35.95 & 1.07 & 1.89 & 5710 \\
\hline 6 & 31.81 & 1.15 & 1.70 & 3816 \\
\hline 7 & 32.56 & 1.08 & 1.83 & 3834 \\
\hline 8 & 34.18 & 1.07 & 1.96 & 4564 \\
\hline
\end{tabular}

The porosity value between $31 \%$ until almost $36 \%$. The surface area result in $1.05-1.19$ different sharply. Then the tortuosity is varying in $1.70-2.01$. The last, the interval value of permeability is 3800 $\mathrm{mD}-5700 \mathrm{mD}$. 
From the data, all sandstone samples have relatively a similar value in porosity. The sandstone sample quite homogenous and very porous sample. Moreover, the value of permeability represents the physical meaning that our sample is very easy to flow the fluid. We try to compare our data with the template that given by Dvorkin et al, 2009 that calculated from Fontaneblau sandstone (Figure 4). The Ngrayong sample relatively following the trend of permeability- porosity values. From the result, we confirm that the sandstone sample is very porous and the connectivity between pores is very good.

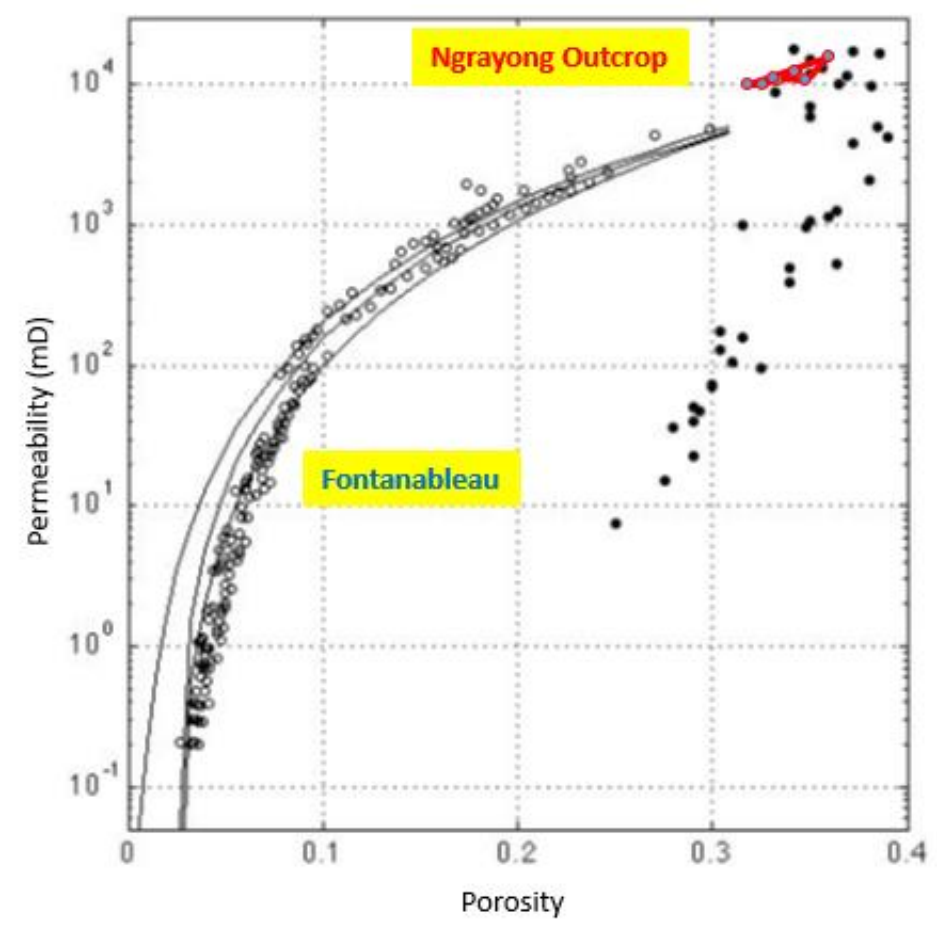

Figure 4. Comparison of porosity-permeability relationship between Fontaneblau sample and Ngrayong sample

\section{Conclusion}

From the digital simulation to prediction physical properties of sandstone sample, it indicate the Ngrayong Outcrop sandstone has dominant porosity upper $30 \%$ and good permeability. From the result, also the sandstone sample is relatively homogeneous.

\section{References}

[1] Andrä, H., Combaret, N., Dvorkin, J., Glatt, E., Han, J., Kabel, M., Keehm, Y., Krzikalla, F., 376 Lee, M., Madonna, C., Marsh, M., Mukerji, T., Saenger, E.H., Sain, R., Saxena, N., Ricker, 377 S., Wiegmann, A., Zhan, X., 2013a. Digital rock physics benchmarks—Part I: imaging and 378 segmentation. Comp. Geosci. 50, 25-32.

[2] Arns, C.H., Knackstedt, M.A., Pinczewski, W.V., Garboczi, E. G., 2002. Computation of linear elastic properties from microtomographic images: methodology and agreement between theory and experiment. Geophysics, 67, 1396-1405.

[3] Bourbié, T., Coussy, O., and Zinszner, B., 1987, Acoustics of Porous Media. Houston, TX: Gulf Publishing Co.

[4] Dvorkin, J., Nur, A., and Yin, H., 1994, Effective Properties of Cemented Granular Materials, Mechanics of Materials, 18, 351-366. Dvorkin, J., and Nur, A., 1996, Elasticity of High Porosity Sandstones: Theory for Two North Sea Datasets, Geophysics, 61, 1363-1370. 
[5] Gomez, C., 2009, Reservoir characterization combining elastic velocities and electrical resistivity measurements. Ph.D. dissertation, Stanford University.

[6] Han, D., 1986, Effects of porosity and clay content on acoustic properties of sandstones and unconsolidated sediments: Ph.D. dissertation, Stanford University.

[7] Handoyo, Fatkhan, Fourier, D.E.L., 2014. Digital Rock Physics Application: Structure Parameters Characterization, Materials Identification, Fluid Modeling, and Elastic Properties Estimation of Saturated Sandstones, HAGI Proceeding 2014 Solo, Bandung Institute of Technology, Indonesia.

[8] Mavko, G., and Nur, A., 2009, The Rock Physics Handbook, Second Edition Tools for Seismic Analysis of Porous Media. Cambridge University Press The Edinburgh Building, Cambridge CB2 8RU, UK

[9] Saxena, Nishank, Day-Stirrat, Ruari J., 2017. Effect of image segmentation \& voxel size on micro-CT computed effective transport \& elastic properties. Marine and Petroleum Geology Article. USA.

[10] Wiegman, et al., 2012. Predicting Effective Elastic Properties with Elastodict. Fraunhofer ITW. Germany.

\section{Acknowledgments}

Thank you for LP3 ITERA for the research funding. 